\title{
Study on Water Structure Change Rule Based on Information Entropy Perspective
}

\author{
Min $\mathrm{Wu}^{1 *}$, Wenyuan Wang ${ }^{1}$, Changfeng Shi ${ }^{1}$ \\ ${ }^{1}$ School of Business Administration, HoHai University, Chang Zhou, Jiang Su, 213022, China \\ *Corresponding author
}

Keywords: Information entropy; equilibrium degree; water use structure; composition data; forecast

\begin{abstract}
This article analyzed the evolution rule of the water use structure in recent years in China based on the information entropy. It is found that water structure tends to disorder, water system equilibrium degree increases, single water trend becomes weak, and water system tends to be complex and stable. The water use structure goes through the process of "orderly but low efficiency " to" disorderly "to" orderly and high efficiency" and presents the form of inverted "U". This study used prediction model of composition data. The predicted proportion of the non-agricultural water will be at $41.1 \%$ in 2026 . The information entropy and equilibrium degree is growing. Finally, the government should increase the water use for ecological, adjust the water use structure and promote the industrial structure up-grade.
\end{abstract}

\section{Introduction}

Water resource is an important resource for human survival and development, and a constraint factor for the sustainable development of China's society, economy and ecology. Human activities have a considerable impact on the structural evolution of water resource development and utilization, so it is necessary to study the structural evolution rule of water system. Information entropy has been widely applied to water system structure evolution rule research. Xiaojun Wang [1], Huan Lei [2], Liming Zhang [3], and Yang Shuo [4] all used the information entropy principle to analyze the evolution rule of water use structure from different perspectives. This paper used information entropy to analyze the evolution rule of water use structure and the composition data-forecasting model to forecast the water structure in the next decade, analyzing the future trend of structure evolution rule of water use system.

\section{Theoretical introduction}

Information entropy was first generated in the field of physics and has been widely used in the field of information theory. Information entropy is introduced into the water use system to measure whether the system structure is orderly, balanced and stable. Within a certain time frame, the total amount of water use is set as $Q$, there are $n$ types of water use, the water consumption of $i(i=1,2, \ldots, n)$ type of utilization is $q_{i}$, then there is $\sum_{i=1}^{n} q_{i}=Q$, use $p_{i}$ to indicate the proportion of $i$ type of water consumption, then there is $p_{i}=\frac{q_{i}}{Q}$, and satisfies $\sum_{i=1}^{n} p_{i}=1$, of course $p_{i} \neq 0 \quad(i=1,2, \ldots, n)$. Then the calculation formula of water structure information entropy is as follows:

$$
H=-\sum_{i=1}^{n} p_{i} \ln p_{i}(i=1,2, \ldots, n)
$$

The range of $H$ is $[0, \ln (n)]$. And the larger the $H$ value, the more disordered the structure of the water system is.

In order to make the information entropy be comparable, and eliminate the influence of water use type on the entropy, the equilibrium degree $\mathrm{E}$ is introduced here. The formula is as follows:

$$
E=\frac{-\sum_{i=1}^{n} p_{i} \ln p_{i}}{\ln (n)}(0 \leq E \leq 1)
$$


The larger $E$ indicates that the single water trend is relatively weak, the water structure is relatively complex, and the water system is more stable. The smaller the value, the water structure is relatively simpler, so the water system is not stable enough.

\section{Data Source and Analysis}

Data in this paper are all from the China Water Resources Bulletin. The total amount of water used consists of agricultural water, process water, domestic water and ecological water. The information entropy $\mathrm{H}$ value and the equilibrium $\mathrm{E}$ value are shown in Fig. 1 and Fig. 2.

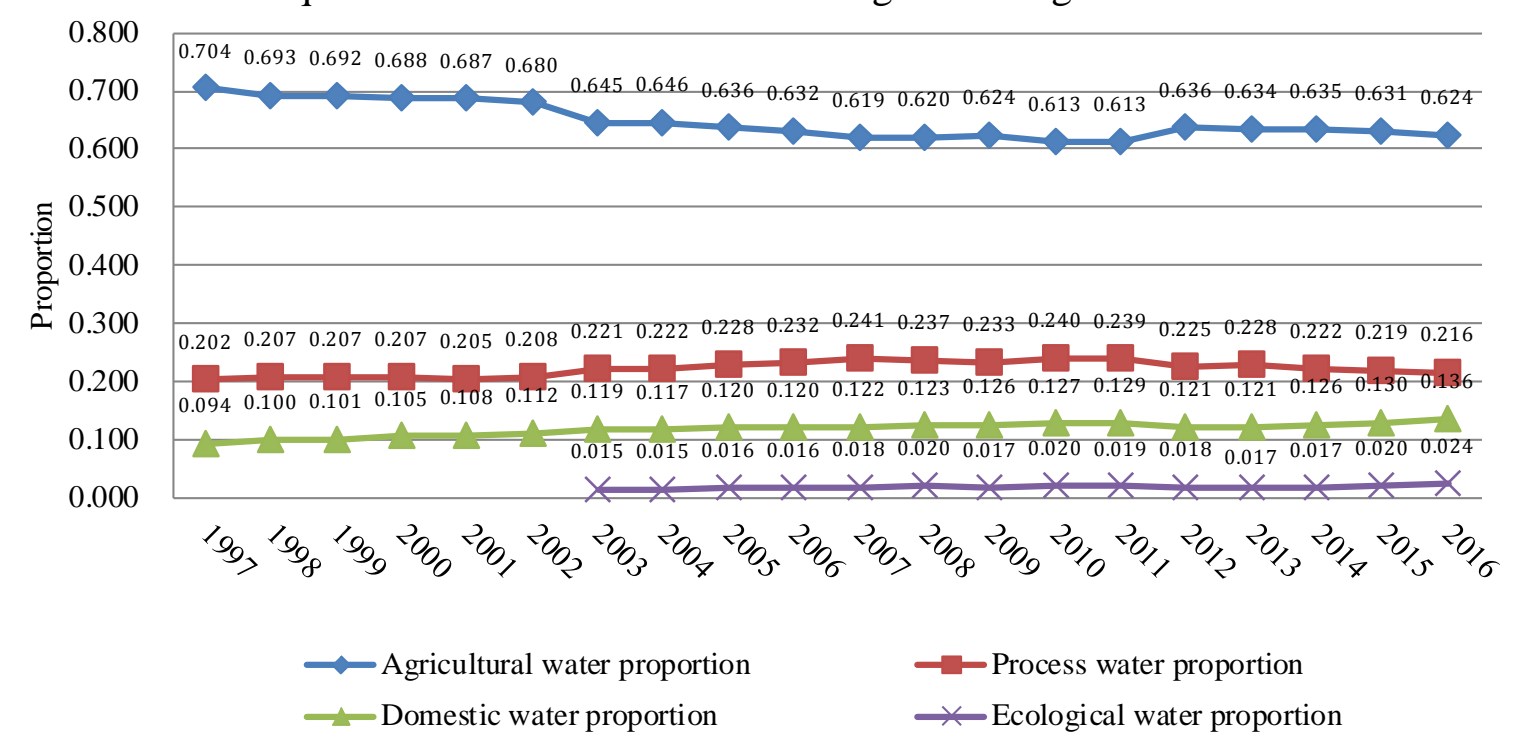

Fig. 1 Trends in water use structure

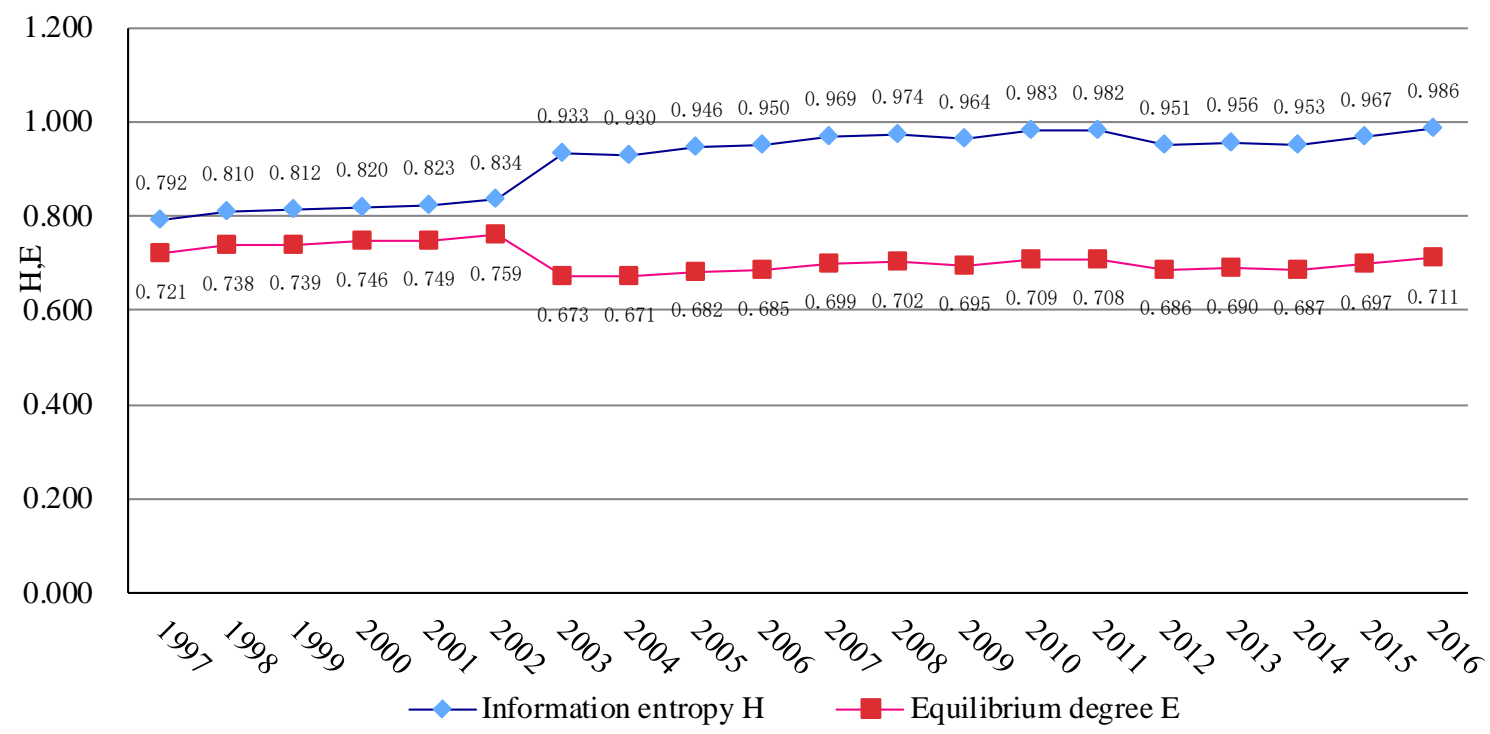

Fig. 2 Information entropy and equilibrium change trend

As shown in Fig. 1 and 2, the proportion of agricultural water use is generally on the decline, with an average annual decline of $0.63 \%$. The proportion of process, domestic and ecological water use is on the rise, with an average annual increase of $0.35 \%, 1.96 \%$ and $3.68 \%$, respectively. In 2003, water classification introduced the ecological water use, so the overall trend of information entropy and equilibrium degree is divided into two periods, the later information entropy $\mathrm{H}$ value is greater than the previous, and the later equilibrium $\mathrm{E}$ value is smaller than the previous, but the information entropy and equilibrium show an increasing trend in the two periods, indicating that the water structure changes greatly, and the water system is in a disordered state. 
This paper also analyzes the changing law of water structure from the perspective of industrial structure. The proportion of primary industry and secondary industry is agricultural water and industrial water respectively, while the proportion of tertiary industry is the sum of the proportion of domestic and ecological water. The information entropy $\mathrm{H}$ and the equilibrium $\mathrm{E}$ are shown in Fig. 3 and Fig. 4. The primary industry water use proportion is decreasing year by year, and the water consumption of the secondary and tertiary industries is increasing year by year. In 2016, primary industrial water consumption proportion was $62.4 \%$, which was $8 \%$ lower than that in 1997 . The proportion of water used in secondary and tertiary industries was $21.6 \%$ and $16 \%$ respectively, which was $1.4 \%$ and $6.6 \%$ higher than that in 1997. The information entropy $\mathrm{H}$ and the equilibrium $\mathrm{E}$ are both increasing. The information entropy in 2016 is 0.92 , which is $15.91 \%$ higher than that in 1997, and the average annual growth rate is $0.78 \%$, indicating that the three industrial water structures are in a disorder and the water structure changes greatly. At the same time, the water system is more complicated and stable.

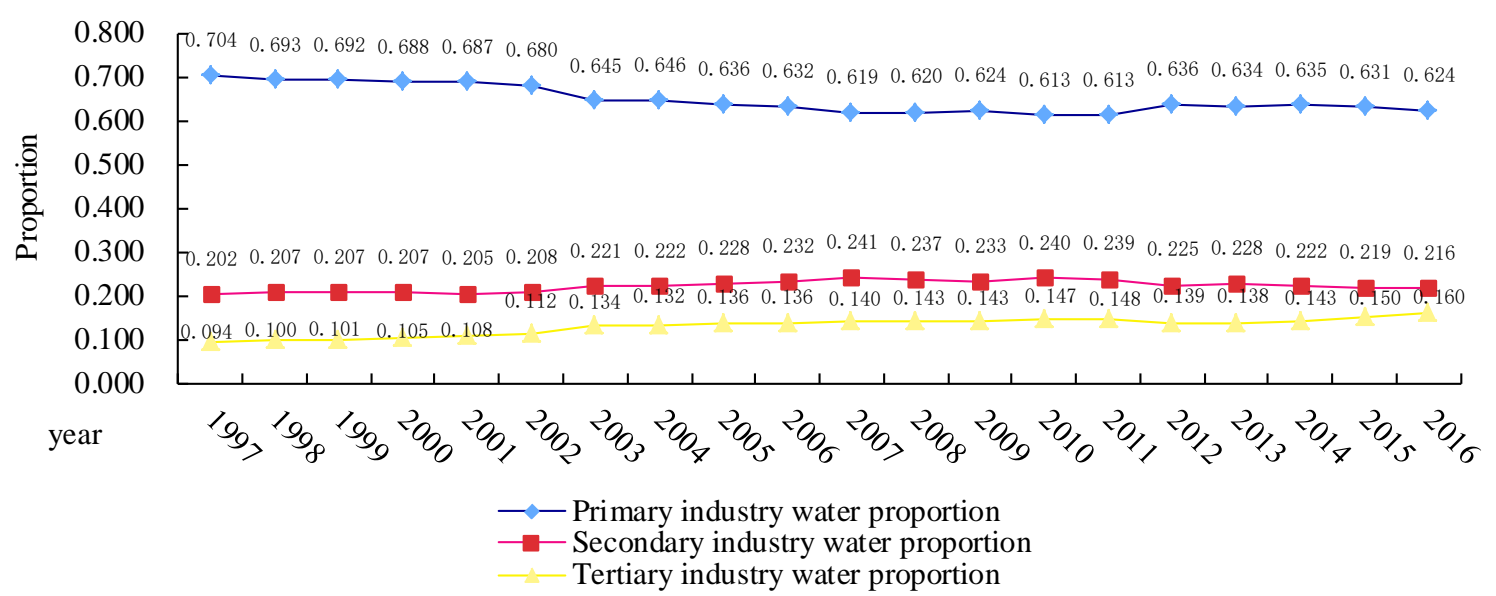

Fig. 3 Changing trend of water structure in three industries

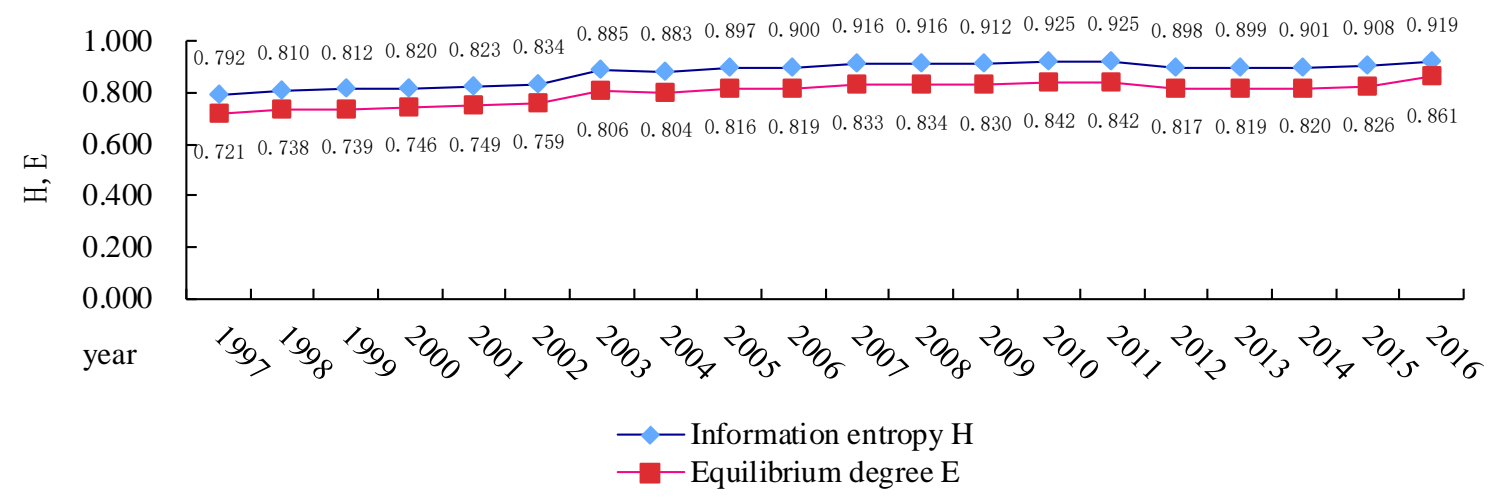

Fig. 4 Trends of information entropy and equilibrium

\section{Forecast of Water Structure Evolution in the Next Decade}

There are many methods for forecasting the evolution rule of water use structure, such as regression forecasting method, exponential smoothing method, etc. In order to eliminate the problem caused by these forecasting method that the proportion of all types of water is not necessarily equal to 1 in the predicted year, this paper used the predictive modeling method of composition data [5-8] to predict the water structure according to the three industrial water types. A sequence of fraction data collected in chronological order:

$$
X^{t}=\left(x_{1}^{t}, x_{2}^{t}, x_{3}^{t}\right), \text { and } \sum_{i=1}^{3} x_{i}^{t}=1,0<x_{i}^{t}<1, t=1,2, \ldots, T
$$


In the formula, $x_{i}^{t}$ represents the proportion of the water consumption of $i$ industry in $t$ year to the total water consumption. This part uses the information before $T$ year to predict the water consumption structure after $T$ year, and then calculates its information entropy and equilibrium degree to reflect the evolution rule of water consumption structure. Affected by the paper length, the calculation process is omitted; the calculation results are shown in table 1.

Table 1 Prediction of the evolution trend of water structure

\begin{tabular}{cccccc}
\hline Year & $\begin{array}{c}\text { Primary industry water } \\
\text { proportion }\end{array}$ & $\begin{array}{c}\text { Secondary industry water } \\
\text { proportion }\end{array}$ & $\begin{array}{c}\text { Tertiary industry water } \\
\text { proportion }\end{array}$ & $\mathrm{H}$ & $\mathrm{E}$ \\
\hline 2017 & 0.650 & 0.184 & 0.164 & 0.8880 & 0.8083 \\
2018 & 0.641 & 0.192 & 0.167 & 0.9008 & 0.8200 \\
2019 & 0.639 & 0.191 & 0.170 & 0.9036 & 0.8225 \\
2020 & 0.635 & 0.191 & 0.174 & 0.9088 & 0.8273 \\
2021 & 0.634 & 0.189 & 0.177 & 0.9103 & 0.8286 \\
2022 & 0.627 & 0.192 & 0.181 & 0.9189 & 0.8364 \\
2023 & 0.607 & 0.208 & 0.185 & 0.9418 & 0.8573 \\
2024 & 0.604 & 0.208 & 0.188 & 0.9453 & 0.8605 \\
2025 & 0.595 & 0.213 & 0.192 & 0.9552 & 0.8694 \\
2026 & 0.589 & 0.216 & 0.195 & 0.9616 & 0.8753 \\
\hline
\end{tabular}

From Table 1, it shows that the changes in the water use structure of the three industries: the proportion of water use in the primary industry is declining, and the proportion of water use in the secondary and tertiary industries is rising. By 2026, water use proportion in the three industries will be 58.9\%, $21.6 \%$ and 19.5\% respectively. Compared with 2016, the water use proportion in the primary industry decreases by 3.5\%, water use proportion in the secondary industry remains unchanged, and water use proportion in the tertiary industry increase by 3.5\%. In 2026, the information entropy will be 0.9616 and the equilibrium will be 0.8753 . Compared with 2016, the two increase by 0.043 and 0.039 , showing an increasing trend and indicating that the water structure continued to be in a state of disorder, at the same time, showing that the water system is relatively stable and balanced, and the single water use trend is not prominent, the proportion of non-agricultural water will reach $41.1 \%$, an increase of $3.5 \%$ over 2016.

\section{Conclusion}

\subsection{The changing trend of water structure is inverted " $U$ "}

During periods of economic underdevelopment, agriculture was in a dominant position, which consumed a large amount of water resources. The single advantage of agricultural water was obvious, the water structure was not complicated, the balance degree of water system was not strong, and the water structure was "orderly but low efficiency ". With the development of economy, water use proportion in industry and services has increased, the single advantage of agricultural water has gradually weakened, and the water system was more complicated and more stable. The water system was in a "disordered" state. When the economy is highly developed, service industry plays an increasingly important role in social economy, and the proportion of service industry water will gradually increase. The water system will not complex, water structure equilibrium degree will be weakened. However, the water use efficiency is very high, and the water structure is in a state of "orderly and high efficiency". Therefore, the water use structure goes through the process of "orderly but low efficiency" $\rightarrow$ "disorderly" $\rightarrow$ "orderly and high efficiency" and the process presents the form of inverted " $U$ ". The current water structure in China is in a "disorderly" state, the proportion of agricultural water use is about $60 \%$, and the proportion of water used in service industry is $15 \%$. It is necessary to adjust the water structure, increase the water consumption of the service industry, and provide support for the development of the service industry. 


\subsection{Adjust water structure and improve water rights trading}

It is necessary to adjust the structure of water use, for agricultural use is much less efficient than industrial use and service use. This paper used the output value (RMBYuan) of the unit $\left(\mathrm{m}^{3}\right)$ water resources to measure water efficiency, which shown in Fig. 5. From the water efficiency data in 2016, the output value of water resources in agriculture, process and service respectively is 17.51 RMB Yuan, 189.5 RMB Yuan and 398.49 RMB Yuan; the ratio is 1: 10.82: 22.76. So the government should improve the water rights trading market, transfer water from low-efficiency agriculture to an efficient service industry, enhance the overall efficiency of the water resources and optimize water resources allocation.

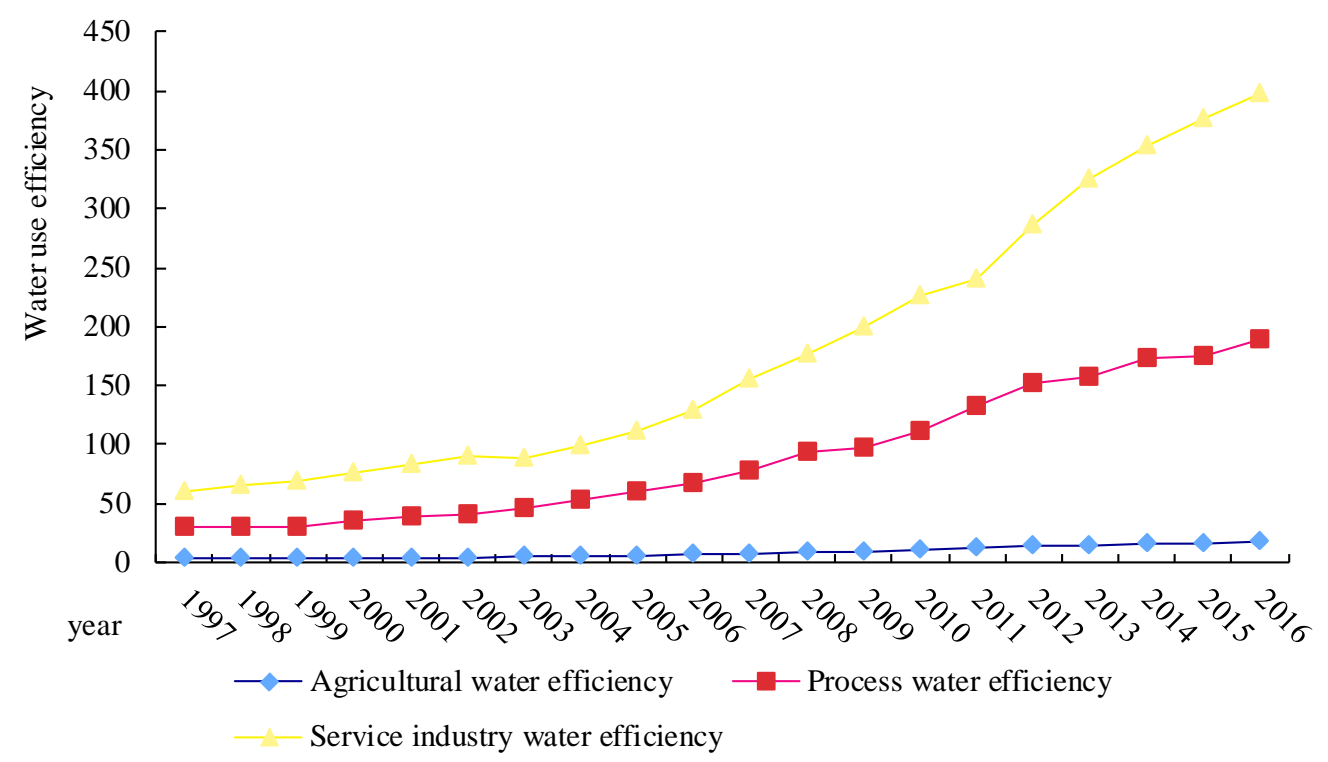

Fig. 5 Water efficiency of different industries

\subsection{Increase ecological water use}

Ecological civilization construction is the important guarantee for sustainable development, and ecological water is the condition to maintain the balance of ecosystem. But the proportion of ecological water in the whole water system in China is very small, which was only $2.4 \%$ in 2016 . Therefore, the order of water resource allocation should be made clear.

\subsection{Adjust industrial structure}

Evolution of industrial structure is an important reason for the evolution of water use structure, and the advanced industrial structure will bring about the optimization and upgrading of water use structure [9]. In 2016, the added value of agriculture, industry and services accounted for $8.6 \%, 39.8 \%$ and $51.6 \%$ of the total value respectively, and the water use ratio was $62.4 \%, 21.6 \%$ and $16 \%$ respectively. But in 1997 , the output value of agriculture, process and services accounted for the proportions were 18.3\%, $41.7 \%$ and $40 \%$ respectively, and the proportion of water use was $70.4 \%, 20.2 \%$ and $9.4 \%$. Agricultural water consumption is gradually shifting to service industry; meanwhile, the optimization of the structure of the water is also a reflection of the change of industrial structure.

\section{Acknowledgement}

This research was financially supported by Youth Foundation of Humanity and Social Science, China Ministry of Education (Grant NO. 18YJC630198) and Youth Foundation of National Natural Science Foundation (Grant NO. 41701613). 


\section{References}

[1]. Xiaojun Wang, Jianyun Zhang, Ruimin He and Yancan Wang, "Study on the Evolution Law of Water Utilization Structure and Regulating (In Chinese)," China Population Resources and Environment, 2011, 2 (21): 61-65.

[2]. Huan Lei and Xin Zhang, “Analysis on water use structure change and its driving forces during last 10 years in Shanxi Province (In Chinese),” Journal of Water Resources \& Water Engineering, 2012, 8 (23): 125-128.

[3]. Liming Zhang, Yan Zhao, Hongrui Wang and Chengzhong Pan, "Study of the relationship between urban economic development and the utilization of water resources in Xi'an City based on information entropy and grey correlation grade (In Chinese)," South to North Water Transfers and Water Science \& Technology, 2017, 15 (4): 187-202.

[4]. Shuo Yang, "Analysis on Evolution of Water Consumption Structure and Driving Forces in Beijing (In Chinese),” Pearl River, 2018, (5): 50-53.

[5]. Huiwen Wang, Zhihui Zhang and Tenenhaus M, "Multiple linear regression modeling method based on the compositional data (In Chinese)," Journal of Management Sciences in China, 2006, 8 (9): 27-32.

[6]. Jinli Hu, Shih Chuan Wang and Fangyu Yeh, "Total-factor water efficiency of regions in China (In Chinese),” Resources Policy, December 2006: 217-230.

[7]. Xueyuan Wang and Liange Zhao, “Agricultural water efficiency and influencing factors in China -SFA analysis based on provincial panel data from 1997 to 2006 (In Chinese),” Issues in Agricultural Economy, 2008, 3: 10-18.

[8]. Manhong Shen, “Science of water resource economics (In Chinese)," Beijing, China Environmental Press, 2008.

[9]. Linhui Fu, “An Empirical Research on Industry Structure and Economic Growth (In Chinese),” Statistical Research, 2010, 8 (27): 79-81. 